\title{
Factors affecting cervical cancer screening uptake, visual inspection with acetic acid positivity and its predictors among women attending cervical cancer screening service in Addis Ababa, Ethiopia
}

\author{
Atalay Mulu Fentie', Tamir Birhanu Tadesse ${ }^{2}$ and Gebremedhin Beedemariam Gebretekle ${ }^{1 *}$ (D)
}

\begin{abstract}
Background: Cervical cancer is the second most common cancer in Ethiopia next to breast cancer. Despite the high burden of the disease and availability of free screening services in Ethiopia, uptake is still trivial. This study aims to identify factors associated with cervical cancer screening uptake, VIA (visual inspection with acetic acid) positivity and its predictors among women attending cervical cancer screening service in Addis Ababa, Ethiopia.

Methods: Concurrent mixed study approach of qualitative interview $(n=15)$ and cross-sectional study among 844 screened women was conducted from February to July 2018. A multistage sampling technique was employed to recruit survey participants from the selected health facilities while the key informants for an in-depth interview were selected purposively. Descriptive statistics were used to summarize the quantitative data and multivariable logistic regression was employed to explore factors associated with VIA positivity of the cervix among screened women. Qualitative data were analyzed using thematic analysis approach.

Results: The VIA positivity of the cervix was $10.3 \%$. Mean age of study participants was $35.74 \pm 7.6$ years and women in the age group of $\geq 45$ years were about $>8$ times more likely to have VIA test positive result compared to younger women ( $\leq 24$ years). Being single ( $A O R=3.2,95 \% \mathrm{Cl}$ : 1.4-7.31), widowed ( $\mathrm{AOR}=18.6,95 \% \mathrm{Cl}$ : 3.8-91.2), initiating sexual intercourse early ( $<16$ years) $(\mathrm{AOR}=2.72 ; 95 \% \mathrm{Cl}: 1.65-4.49)$, and having two or more lifetime sexual partners (AOR $=4.9 ; 95 \% \mathrm{Cl}: 1.31-8.75)$ were also found to be predictors of being VIA positive. Lack of awareness, inaccessibility of the screening service, cultural beliefs and negative perception towards cancer were found to be the major reasons for low uptake of cervical cancer screening.

Conclusion: The VIA positivity among screened women in Addis Ababa was found to be moderately low compared to reports in other parts of Ethiopia. Having multiple sexual partners, being older age and initiation of sexual intercourse at an early age were associated with VIA positivity of the cervix. Thus, concerted efforts must be taken to increase accessibility of screening services and improve awareness regarding cervical cancer screening.
\end{abstract}

Keywords: Cervical cancer, Screening uptake, VIA positivity, VIA test

\footnotetext{
* Correspondence: gebremedhin.beedemariam@aau.edu.et

'Social and Administrative Pharmacy Unit, School of Pharmacy, College of Health Sciences, Addis Ababa University, P.O.Box: 1176, Addis Ababa, Ethiopia

Full list of author information is available at the end of the article
}

(c) The Author(s). 2020 Open Access This article is licensed under a Creative Commons Attribution 4.0 International License, which permits use, sharing, adaptation, distribution and reproduction in any medium or format, as long as you give appropriate credit to the original author(s) and the source, provide a link to the Creative Commons licence, and indicate if changes were made. The images or other third party material in this article are included in the article's Creative Commons licence, unless indicated otherwise in a credit line to the material. If material is not included in the article's Creative Commons licence and your intended use is not permitted by statutory regulation or exceeds the permitted use, you will need to obtain permission directly from the copyright holder. To view a copy of this licence, visit http://creativecommons.org/licenses/by/4.0/. The Creative Commons Public Domain Dedication waiver (http://creativecommons.org/publicdomain/zero/1.0/) applies to the data made available in this article, unless otherwise stated in a credit line to the data. 


\section{Background}

Cervical cancer is a global significant public health problem; especially in low-income countries, where it is the second most commonly diagnosed cancer and third leading cause of cancer-related deaths in women. Globally, it is the fourth common cancer accounting for $6.6 \%$ of all female cancers $[1,2]$. About $85 \%$ of the global burden and $87 \%$ of deaths secondary to cervical cancer occur in the less developed regions. East African region was the top in cervical cancer with age-standardized incidence of 42.7 per 100,000 population and mortality rate of 27.6 per 100,000 deaths [3]. In Ethiopia, cervical cancer is the second most common female cancer with an age-standardized incidence rate estimated in 2018 of 18.9/100,000 (about 6294 new cases and 4884 deaths estimated annually) $[4,5]$.

Considering its increasing burden, recently Ethiopia has put in place a strategic goal to reduce cancer incidence and mortality by $15 \%$ by 2020 . This was in alignment with the 5 years National Health Sector Transformation Plan of 2016-2020 which aimed to increase awareness by $50,80 \%$ coverage of vaccination against Human Papilloma Virus (HPV) and 80\% screening coverage using visual inspection with acetic acid (VIA) testing among non-symptomatic women aged early 30-49 years. Like other resource limited settings, cervical cancer screening strategy of Ethiopia preferred VIA screening method in detecting precancerous cervical lesions. The VIA test method was chosen since it does not need more advanced testing requirements (e.g. trained cytotechnicians or pathologists and other programmatic requirements) as compared to HPV test and cytologic or Pap smear. As per the guideline, abnormalities are identified by inspection of the cervix without magnification after application of dilute acetic acid (vinegar). When vinegar is applied to abnormal cervical tissue, it temporarily turns to white (aceto-white) allowing the provider to make an immediate assessment of a positive (abnormal) or negative (normal) result [6].. The VIA test has been also shown to have an average sensitivity of $77 \%$ (ranged from 56 to $94 \%$ ) and specificity of $86 \%$ (ranged from 74 to $94 \%$ ) to detect precancerous lesions and cancer of the cervix. However, the major limitation of VIA test is its use in older women. Visual tests cannot be relied on in postmenopausal women, because the transformation zone of these women is often inside the cervical canal $[7,8]$.

To achieved Ethiopia's 2020 ambitious goals, cervical cancer screening services are being provided free for all eligible women since 2016 [6]. Despite the availability of guideline for cervical cancer prevention and control; screening was not fully implemented in all health care centers [4] and its uptake among the community is still very low (7.3 to $23.5 \%$ ) [9-15]. This could be attributed to lack of awareness about the importance and availability of cervical cancer screening services, perception about cancer, risk factors and prevention methods [12, 15-19]. On the other hand, screening uptakes as well as knowledge about cervical cancer risk factors and preventions are low among the health workers [20]. Hence, our study aimed to identify factors associated with uptake of cervical cancer screening and VIA positivity among screened women. Findings of the study could be used to inform public policy, develop and implement strategies to increase screening uptake and thereby contribute in reducing the high morbidity and mortality of the disease in the country.

\section{Methods}

\section{Study area}

The study was conducted in Addis Ababa, the capital city of Ethiopia and headquarters of Africa Union. It is also the largest city with population size of 7 million where male to female ratio is 99:100. Number of females in the reproductive age group (15-49 years) constitutes $35.5 \%$ of the total population. Administratively, Addis Ababa has 10 sub-cities with a total of 96 health centers and 43 hospitals (12 public and 31 private). The general health services coverage in Addis Ababa with regard to geographical accessibility is almost $100 \%$ [6].

\section{Study design and population}

A concurrent mixed study approach of both quantitative and qualitative methods was conducted from February 1 to July 31, 2018. A cross-sectional study was carried out to determine the prevalence and factors associated with VIA positivity among women who had been screened for cervical cancer in the selected health facilities. The qualitative interview was carried out with women in the community (screened and not screened) to explore factors affecting screening uptake.

\section{Participants' recruitment}

Among 139 healthcare facilities, cervical cancer screening service was rendered in 25 health centers and five hospitals. Of these, health centers perform only VIA test for screening. But hospitals are doing Pap smear to further investigate referred women with VIA test positive. Hence, all of our participants were recruited from health centers using a multistage random sampling technique. From the 10 sub-cities, five sub-cities and one health center from each sub-city were selected using simple random sampling technique. The total numbers of women screened in the selected health centers were 1200 and of these, we included 844 women. Sample size was calculated using a formula for single population proportion which was calculated to be 384 [21]. Then, considering a $10 \%$ inappropriate response and design effect 
of two, we included a total of 844. Proportional allocation of survey participants was done among the selected facilities (Fig. 1) and participants were drawn using a systematic random sampling technique.

For the qualitative interview, a purposive sampling technique was employed to select the key informants. We recruited all interviewees by consulting the health community workers who have been tasked with creating awareness and increasing uptake of the screening program. We included women who refused to be screened, not yet visited for screening and those who had been screened for cervical cancer.

\section{Data collection procedures and instruments}

For the quantitative survey, data were collected from the screening registration logbook using a specifically designed form to capture participant's socio-demographic characteristics (age, marital status and residence), reproductive characteristics (menstrual history, pregnancy status and parity, contraceptive use history and type of contraceptive used, family history of cervical cancer, HIV status and STI history), behavioral characteristics (age at first sexual intercourse, lifetime sexual partners, smoking habit and previous history of cervical cancer screening) and screening test result. The survey form was developed based on screening registration logbook developed by our ministry of health (Additional file 1). Data were collected by 10 trained nurses.
For the qualitative interview, we used a semistructured open interview guide with flexible probing technique (Additional file 1). It was initially developed by the research team in English, translated to Amharic (local and national language) and back-translated into English to ensure consistency. Participants were encouraged to speak and express their ideas freely and describe their experiences with cases related to the topic. All interviews were conducted by author $\mathrm{TB}$ in Amharic, tape-recorded, and translated and transcribed verbatim on the same day of the interview. Interviews of participants continued until saturation was reached, meaning the investigator agreed that there was redundancy in the responses and there was no new idea emerging.

\section{Data analysis}

Quantitative data were entered and analyzed using SPSS version 24. Descriptive statistics such as proportion, mean and standard deviation were used to summarize participants' characteristics. Associations between the outcome variable (status of cervical lesions using VIA test) and explanatory variables were tested using multivariable logistic regression. A $p$-value of $\leq 0.25$ was taken as a cutoff point for selecting variables for the multivariable logistic regression model. The results of all the logistic regression analysis are reported as odds ratios (OR) with 95\% confidence intervals (CIs). Chi-square test was also performed to see association between

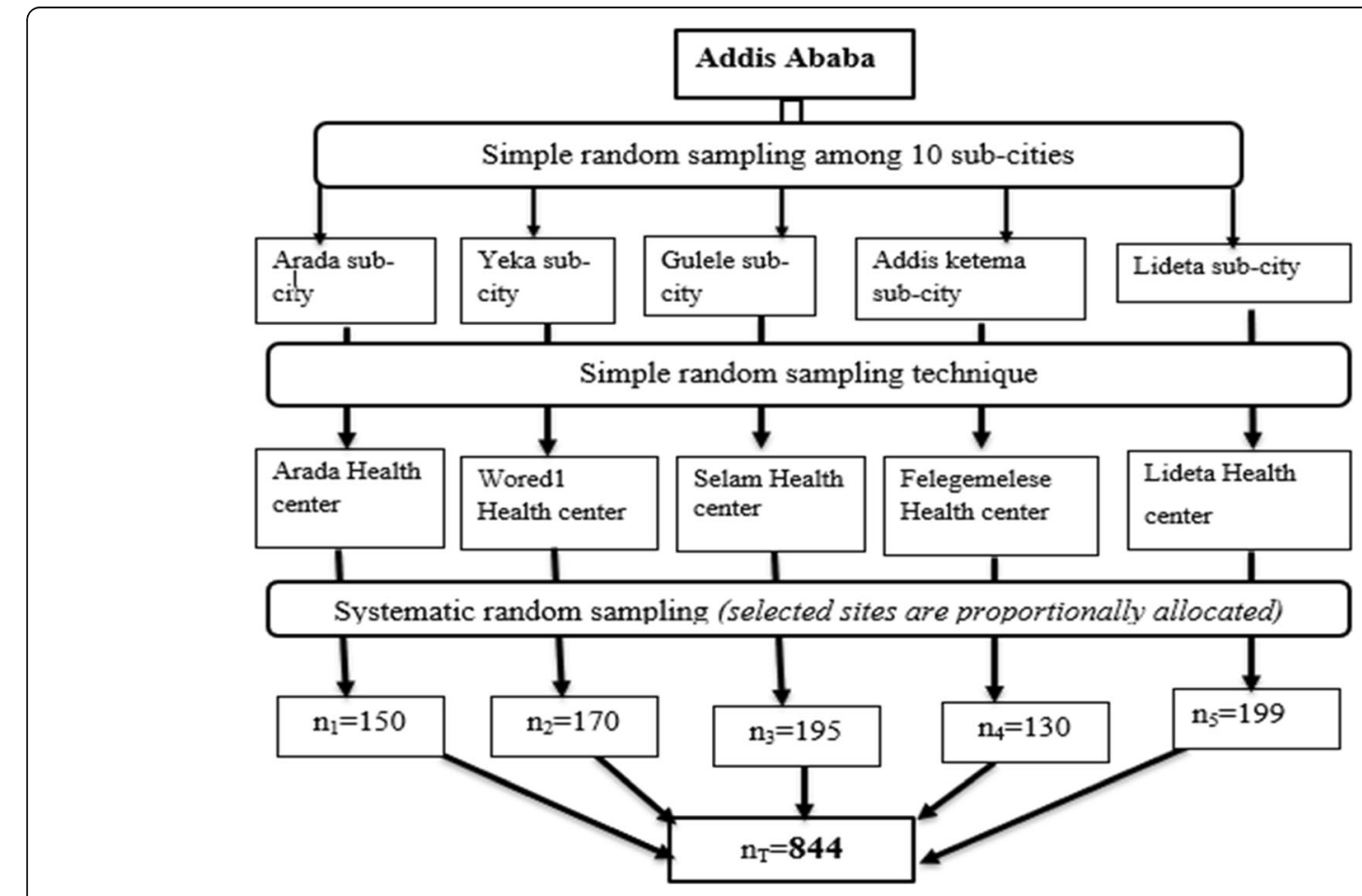

Fig. 1 Flow chart of participant enrollment for the quantitative surveys 
health centers and VIA positivity, sociodemographic, sexual and reproductive characteristics. The VIA positivity differences between clusters (health centers) were tested using generalized linear mixed (melogit) model for binary logistic regression analysis. As per the melogit model, the between group variance value was computed using the statistical package for complex survey data (STATA 14.1). Then intra cluster correlation coefficient (ICC) for a categorical outcome was calculated using the following formula [22].

$\mathrm{ICC}=$ Between group variance $/\left(\right.$ Between group variance $+\boldsymbol{\pi}^{2} / 3$ )

Qualitative data were analyzed manually using thematic analysis. Each interview was read thoroughly text by text and codes were labeled. Then, codes were categorized into different categories and finally, themes were formulated. The qualitative finding was shared with seven of the interviewees to confirm if interpretation was reflective of their perception and/or experiences.

\section{Results}

Results of quantitative survey

Socio-demographic and behavioral characteristics of survey participants

The mean age of the participants was $35.7 \pm 7.6$ years and majorities $(75.8 \%)$ of them were in the age group of $26-40$ years. Almost all (99.4\%) of the women were living in Addis Ababa and 696 (82.5\%) of them were married. With regard to their age at first sexual intercourse, majorities (69.2\%) of them had first sexual intercourse at the age between 16 to 24 years. Only very few $(1.3 \%)$ of them had smoking history but about two-third (66\%) had multiple sexual partners. None of the participants had previous history of cervical cancer screening (Table 1).

\section{Sexual and reproductive history}

The majorities $(85.9 \%)$ of women had at least one live birth in their lifetime and most (68.1\%) of them gave 1 to 3 live births. About one-third (34.4\%) of the women had irregular menstrual cycles. The bulks (66.5\%) of the participants never used any type of contraceptive methods. Of those who ever used contraceptives, $102(36.2 \%)$ of them used implants. Only $5(0.6 \%)$ of the women had family history of cervical cancer and 252(29.9\%) of them were HIV-positive. Two hundred forty-seven (29.3\%) women had at least one time sexually transmitted infection (STI) history. From the 844 screened women, $87(10.3 \%)$ of them were detected to be VIA positive indicating the presence of precancerous lesions of the cervix (Table 2).

\section{Factors associated VIA positivity among women's screened for cervical cancer}

Logistic regression analysis showed that women's age, marital status, age at first sexual intercourse, lifetime sexual partners and HIV status were significantly associated with the rate of positive VIA test result. Screened women aged 45 to 54 years $(\mathrm{AOR}=8.1 ; 95 \% \mathrm{CI}$ : 1.53 42.3 ) and $\geq 55$ years $(\mathrm{AOR}=8.4 ; 95 \% \mathrm{CI}$ : $1.1-72.3)$ were more than eight times more likely to have cervical lesions as per VIA test compared to younger counterparts ( $\leq 24$ years). Being single $(\mathrm{AOR}=3.2,95 \% \mathrm{CI}$ : $1.4-7.31)$ and widowed $(\mathrm{AOR}=18.6 ; 95 \% \mathrm{CI}$ : $3.8-91.2)$ were also found to be predictors of having cervical lesions as per VIA test. Women who started sexual intercourse before the age of 16 years were about three times $(\mathrm{AOR}=2.72$; 95\% CI: 1.65-4.49) more likely to have cervical lesions as per VIA test than their counterparts. Moreover, women who had two or more lifetime sexual partners were significantly associated with cervical lesions $(\mathrm{AOR}=4.9$; 95\% CI: 1.31-8.75). In addition, HIV positive women $(\mathrm{AOR}=2.59,95 \% \mathrm{CI}$ : $1.56-4.25)$ were more likely to have cervical lesions compared to HIV negative women (Table 3). Given that small numbers of VIA positive results (87 VIA positive cases out of 844 screened women) and differences with respect to sociodemographic, sexual and reproductive characteristics (Tables 1 and 2) among health centers (clusters), we would expect much variation in the actual number of VIA positivity reported in each cluster and consequently, it is important to estimate ICC. This is shown with our estimate of ICCs (0.069) for observed VIA positivity among women screened for cervical cancer in Table 3.

\section{Findings of qualitative interview}

In-depth interviews were conducted with 15 women their mean age was $35.8 \pm 5.4$ years (ranged from 23 to 55 years). Regarding parity, four of them didn't give live birth whereas six, three and two of them had 1 to 3,4 to 5 and $>5$ live births in their lifetime, respectively. Twelve of them were married and the rest were single. We asked all women to describe the perceived factors that they believe are affecting the screening uptake of cervical cancer. Accordingly, main themes emerged as the key barriers for women to undergo cervical cancer screening were lack of awareness, inaccessibility of the screening service, cultural and religious beliefs.

\section{Lack of awareness}

Most of the respondents were familiar with the word cervical cancer and their source of information was from neighborhoods and mass Medias such as radio and television. When they were asked about cervical cancer, however, they often referred their knowledge to cancer in general. A woman with screening history stated that: 
Table 1 Socio-demographic and behavioral characteristics of women screened for cervical cancer, Addis Ababa, Ethiopia

\begin{tabular}{|c|c|c|c|c|c|c|}
\hline \multirow[t]{2}{*}{ Variables, $n=844$} & \multirow[t]{2}{*}{$n(\%)$} & \multicolumn{5}{|c|}{ Name of health center } \\
\hline & & $\mathrm{AH}$ & W1H & $\mathrm{SH}$ & $\mathrm{FMH}$ & $\mathrm{LH}$ \\
\hline \multicolumn{7}{|c|}{ Age (in years), $p=0.008$} \\
\hline $15-24$ & $54(6.4)$ & $19(12.7)$ & $9(5.3)$ & $6(3.1)$ & $9(6.9)$ & $11(5.5)$ \\
\hline $25-34$ & $343(40.7)$ & $48(32.0)$ & $70(41.2)$ & $94(48.2)$ & $55(42.3)$ & $76(38.2)$ \\
\hline $35-45$ & $359(42.5)$ & $61(40.7)$ & $69(40.6)$ & $76(39.0)$ & $61(46.9)$ & $92(46.2)$ \\
\hline $46-55$ & $77(9.1)$ & $20(13.3)$ & $19(11.2)$ & $18(9.2)$ & $3(2.3)$ & $17(8.6)$ \\
\hline$>55$ & $11(1.3)$ & $2(1.3)$ & $3(1.7)$ & $1(0.5)$ & $2(1.6)$ & $3(1.5)$ \\
\hline \multicolumn{7}{|l|}{ Residence, $p=0.410$} \\
\hline Addis Ababa (AA) & $841(99.4)$ & $149(99.3)$ & $170(100.0)$ & $194(99.5)$ & $130(100.0)$ & $198(99.5)$ \\
\hline Outside AA & $3(0.6)$ & $1(0.7)$ & $0(0)$ & $1(0.5)$ & $0(0)$ & $1(0.5)$ \\
\hline \multicolumn{7}{|l|}{ Marital status, $p=0.02$} \\
\hline Single & $87(10.3)$ & $30(20.0)$ & $21(12.4)$ & $12(6.2)$ & $5(3.8)$ & $19(9.5)$ \\
\hline Married & $696(82.5)$ & $112(74.7)$ & $141(82.9)$ & $169(86.6)$ & $111(85.4)$ & $163(81.9)$ \\
\hline Divorced & $53(6.3)$ & $8(5.3)$ & $7(4.1)$ & $12(6.2)$ & $12(9.2)$ & $14(7.0)$ \\
\hline Widowed & $8(0.9)$ & $0(0)$ & $1(0.6)$ & $2(1.0)$ & $2(1.6)$ & $3(1.6)$ \\
\hline \multicolumn{7}{|c|}{ Ever habit of smoking, $p=0.653$} \\
\hline Yes & $11(1.3)$ & $3(2.0)$ & $2(1.2)$ & $3(1.5)$ & $0(0)$ & $3(1.5)$ \\
\hline No & $833(98.7)$ & $147(98.0)$ & $168(98.8)$ & $192(98.5)$ & $130(100.0)$ & $196(98.5)$ \\
\hline \multicolumn{7}{|c|}{ Age at first sexual intercourse, $p<0.0001$} \\
\hline$\leq 15$ & $174(20.6)$ & $22(14.7)$ & $21(12.4)$ & $40(20.5)$ & $17(13.1)$ & $49(24.6)$ \\
\hline $16-24$ & $584(69.2)$ & $103(68.7)$ & $97(57.1)$ & $118(60.5)$ & $68(52.3)$ & $126(63.3)$ \\
\hline $25-34$ & $81(9.6)$ & $25(16.6)$ & $51(30.0)$ & $35(17.9)$ & $45(34.6)$ & $23(11.6)$ \\
\hline $35-44$ & $5(0.6)$ & $0(0)$ & $1(0.5)$ & $2(1.1)$ & $0(0)$ & $1(0.5)$ \\
\hline \multicolumn{7}{|c|}{ Life time sexual partners, $p<0.0001$} \\
\hline 1 & $287(34.0)$ & $56(37.3)$ & $74(43.5)$ & $57(29.2)$ & $52(40.0)$ & $48(24.1)$ \\
\hline$\geq 2$ & $557(66.0)$ & $94(62.7)$ & $96(56.5)$ & $138(70.8)$ & $78(60.0)$ & $151(75.9)$ \\
\hline \multicolumn{7}{|c|}{ Previously screened for cervical cancer } \\
\hline Yes & $0(0.0)$ & $0(0)$ & $0(0)$ & $0(0)$ & $0(0)$ & $0(0)$ \\
\hline No & $844(100)$ & $150(100)$ & $170(100)$ & $195(100)$ & $130(100)$ & $199(100)$ \\
\hline
\end{tabular}

$p$-value is as per chi-square test done between demographic characteristics and health center type, $A H$ Arada health center, $W 1 H$ Woreda 1 health center, $S H$ Selam health center, FH Felegemelese health center, $L H$ Lideta health center.

"I heard the word cervical cancer in television advertising and in some radio programs but I don't have full information because the programs are too short and they didn't transmit the full information. It is a simple advertisement and what I heard is simply a promotion to be screened for cervical cancer."

On the other hand, majority of the respondents lacked adequate information about the cause of cervical cancer and only two participants responded correctly that having multiple sexual partners as the cause of cervical cancer and they heard it from their neighborhoods. Many respondents perceived cancer and by extension cervical cancer as a deadly disease with no cure. They related the experiences of their friends and/or family members who died of cervical or other cancers. All stated cervical cancer; and cancer in general as a horrible disease and one that often incurred huge stress, emotions and physical suffering on both the patient and their family members.

Even though most respondents heard about cervical cancer, most of them did not know about the sign and symptoms of the disease. Absence of the symptoms was mentioned as a barrier for cervical cancer screening. The community gave priorities to diseases with significant signs and symptoms. One of the participant screened for cervical cancer stressed that;

"I think the reason why most women are not screened for cervical cancer is mainly attributed to the nature of the disease. I mean, at that stage they 
Table 2 Sexual and reproductive history of women screened for cervical cancer and proportion of VIA positivity, Addis Ababa, Ethiopia

\begin{tabular}{|c|c|c|c|c|c|c|}
\hline \multirow[t]{2}{*}{ Variable, $n=844$} & \multirow[t]{2}{*}{$n(\%)$} & \multicolumn{5}{|c|}{ Name of health center } \\
\hline & & $\mathrm{AH}$ & $\mathrm{W} 1 \mathrm{H}$ & $\mathrm{SH}$ & $\mathrm{FMH}$ & $\mathrm{LH}$ \\
\hline \multicolumn{7}{|c|}{ Menstrual History, $p=0.011$} \\
\hline Regularly & $382(45.3)$ & $74(49.3)$ & $77(45.3)$ & $92(47.2)$ & $57(43.8)$ & $82(41.2)$ \\
\hline Irregular & $290(34.4)$ & $49(32.7)$ & $64(37.6)$ & $63(32.3)$ & $55(42.3)$ & 59 (29.6) \\
\hline Post coital spotting & $7(0.8)$ & $0(0)$ & $4(2.4)$ & $1(0.5)$ & $1(0.8)$ & $1(0.5)$ \\
\hline Menopause & $165(19.5)$ & $27(18.0)$ & $25(14.7)$ & $39(20.0)$ & $17(13.1)$ & $57(28.6)$ \\
\hline \multicolumn{7}{|c|}{ Pregnancy status, $p=0.896$} \\
\hline Pregnant & $1(0.1)$ & $0(0)$ & $0(0)$ & $1(0.5)$ & $0(0)$ & $0(0)$ \\
\hline Non-pregnant & $843(99.9)$ & $150(100)$ & $170(100)$ & $194(99.5)$ & $130(100)$ & $199(100)$ \\
\hline \multicolumn{7}{|l|}{ Parity, $p=0.004$} \\
\hline No & $119(14.1)$ & $31(20.7)$ & $28(16.5)$ & $25(12.8)$ & $6(4.6)$ & 29 (14.6) \\
\hline $1-3$ & $575(68.1)$ & $89(59.3)$ & $99(58.2)$ & $136(69.7)$ & $115(88.5)$ & $136(68.3)$ \\
\hline $4-5$ & $107(12.7)$ & $24(16.0)$ & $32(18.8)$ & $21(10.8)$ & $4(3.1)$ & $26(13.1)$ \\
\hline$>5$ & $43(5.1)$ & $6(4.0)$ & $11(6.5)$ & $13(6.7)$ & $5(3.8)$ & $8(4.0)$ \\
\hline \multicolumn{7}{|c|}{ Ever use of contraceptive methods, $p=0.009$} \\
\hline No & $561(66.5)$ & $107(71.3)$ & $117(68.8)$ & $129(66.2)$ & $69(53.1)$ & $139(69.8)$ \\
\hline Yes & $283(33.5)$ & $43(28.7)$ & $53(31.2)$ & $66(33.8)$ & $61(46.9)$ & $60(30.2)$ \\
\hline \multicolumn{7}{|c|}{ Type of contraceptive method, $p=0.317$} \\
\hline Injectable & $86(30.4)$ & $12(27.9)$ & $14(26.9)$ & $22(33.3)$ & $20(33.3)$ & $18(30.0)$ \\
\hline OCP & $42(14.8)$ & $10(23.4)$ & $8(15.4)$ & $11(16.7)$ & $5(8.4)$ & $6(10.0)$ \\
\hline IUCD & $45(15.9)$ & $8(18.6)$ & $10(19.2)$ & $11(16.7)$ & $3(5.0)$ & $13(21.7)$ \\
\hline Implant & $102(36.0)$ & $11(25.6)$ & $19(36.5)$ & $19(28.8)$ & $30(50.0)$ & $23(38.3)$ \\
\hline Tubaligation & $1(0.4)$ & $0(0)$ & $0(0)$ & $1(1.5)$ & $0(0)$ & $0(0)$ \\
\hline Condom & $7(2.5)$ & $2(4.5)$ & $1(1.9)$ & $2(3.0)$ & $2(3.3)$ & $0(0)$ \\
\hline \multicolumn{7}{|c|}{ Other corticosteroid use history, $p=0.556$} \\
\hline Yes & $2(0.2)$ & $1(0.7)$ & $0(0)$ & $0(0)$ & $1(0.8)$ & $0(0)$ \\
\hline No & $842(99.8)$ & $149(99.3)$ & $170(100)$ & $195(100)$ & $129(99.2)$ & $199(100)$ \\
\hline \multicolumn{7}{|c|}{ Family $h x$ of cervical cancer, $p=0.687$} \\
\hline Yes & $5(0.6)$ & $2(1.3)$ & $1(0.6)$ & $1(0.5)$ & $0(0)$ & $1(0.5)$ \\
\hline No & 839 (99.4) & $148(98.7)$ & $169(99.4)$ & $194(99.5)$ & $130(100)$ & $198(99.5)$ \\
\hline \multicolumn{7}{|l|}{ HIV status, $p<0.0001$} \\
\hline HIV positive & $252(29.9)$ & $64(42.7)$ & $56(32.9)$ & $35(26.9)$ & $53(27.2)$ & $46(23.1)$ \\
\hline HIV negative & $447(53.0)$ & $47(31.3)$ & $81(47.6)$ & $48(36.9)$ & $124(63.6)$ & $146(73.4)$ \\
\hline Unknown & $145(17.1)$ & $39(26)$ & $33(19.4)$ & $47(36.2)$ & $18(9.2)$ & $7(3.5)$ \\
\hline \multicolumn{7}{|l|}{ STI history } \\
\hline Yes & $247(29.3)$ & $16(10.7)$ & $44(25.9)$ & $55(28.2)$ & $65(50.0)$ & $67(33.7)$ \\
\hline No & $597(70.7)$ & $134(89.3)$ & $126(74.1)$ & $140(71.8)$ & $65(50.0)$ & $132(66.3)$ \\
\hline \multicolumn{7}{|l|}{ VIA test result, $p<0.0001$} \\
\hline Positive & $87(10.3)$ & $8(5.3))$ & $8(4.7)$ & $30(25.4)$ & $11(8.5))$ & $30(25.1)$ \\
\hline Negative & 757 (89.7) & $142(94.7$ & $162(95.3)$ & $165(84.6)$ & $119(91.5$ & $169(84.9)$ \\
\hline
\end{tabular}


Table 3 Univariate and multivariable logistic regression analysis results for predictors of VIA positivity among women screened for cervical lesion, Addis Ababa, Ethiopia

\begin{tabular}{|c|c|c|c|c|}
\hline \multirow[t]{2}{*}{ Variable } & \multicolumn{2}{|c|}{ Screening result, n (\%) } & \multirow[t]{2}{*}{ COR $(95 \% \mathrm{Cl})$} & \multirow[t]{2}{*}{ AOR $(95 \% \mathrm{Cl})$} \\
\hline & Positive & Negative & & \\
\hline \multicolumn{5}{|l|}{ Age (in years) } \\
\hline$\leq 24$ & $2(2.3)$ & $52(6.9)$ & 1.00 & 1.00 \\
\hline $25-34$ & $27(31.0)$ & $316(36.9)$ & $2.2(0.5-9.6)$ & $2.4(0.51-11.5)$ \\
\hline $35-44$ & $40(46.0)$ & $319(42.1)$ & $3.26(0.77-13.9)$ & $3.8(0.81-18.2)$ \\
\hline $45-54$ & $15(17.2)$ & $62(8.1)$ & $6.3(1.4-28.8)$ & $8.1(1.53-42.3)$ \\
\hline$\geq 55$ & $3(3.5)$ & $8(3.0)$ & $9.8(1.4-67.7)$ & $8.4(1.1-72.3)$ \\
\hline \multicolumn{5}{|l|}{ Marital status } \\
\hline Married & $62(71.3)$ & $634(83.8)$ & 1.00 & 1.00 \\
\hline Single & $12(13.8)$ & $75(9.9)$ & $1.6(0.8-3.2)$ & $3.2(1.4-7.31)$ \\
\hline Divorced & $8(9.2)$ & $45(5.9)$ & $1.8(0.8-4.1)$ & $1.8(0.76-4.27)$ \\
\hline Widowed & $5(5.7)$ & $3(0.4)$ & $17.1(4.1-72.9)$ & $18.6(3.8-91.2)$ \\
\hline \multicolumn{5}{|l|}{ Parity } \\
\hline Null Para & $11(12.6)$ & $108(14.3)$ & 1.00 & 1.00 \\
\hline Multi Para & $64(73.6)$ & $568(75.0)$ & $1.1(0.56-2.2)$ & $1.7(0.72-4.0)$ \\
\hline Grand multi Para & $12(13.8)$ & $81(10.7)$ & $1.46(0.61-3.5)$ & $1.9(0.63-5.52)$ \\
\hline \multicolumn{5}{|c|}{ Age at first sexual intercourse } \\
\hline$\geq 16$ years & $52(59.8)$ & $617(81.5)$ & 1.00 & 1.00 \\
\hline$<16$ years & $35(40.2)$ & $140(18.5)$ & $3.1(1.86-4.73)$ & $2.72(1.65-4.49)$ \\
\hline \multicolumn{5}{|l|}{ Ever use of contraceptive } \\
\hline No & $59(67.8)$ & $502(66.3)$ & 1.00 & 1.00 \\
\hline Yes & $28(32.2)$ & $255(33.7)$ & $0.93(0.58-1.51)$ & $0.64(0.37-1.11)$ \\
\hline \multicolumn{5}{|l|}{ Smoking habit history } \\
\hline No & $86(98.8)$ & $747(98.7)$ & 1.00 & 1.00 \\
\hline Yes & $1(1.2)$ & $10(11.3)$ & $0.88(0.11-6.87)$ & $1.25(0.13-11.8)$ \\
\hline \multicolumn{5}{|c|}{ Lifetime number of sexual partners } \\
\hline 1 & $15(17.2)$ & $272(35.9)$ & 1.00 & 1.00 \\
\hline$\geq 2$ & $72(82.8)$ & $485(64.1)$ & $5.6(1.9-9.82)$ & $4.9(1.31-8.75)$ \\
\hline \multicolumn{5}{|l|}{ HIV status } \\
\hline HIV negative & $34(39.1)$ & $413(54.6)$ & 1.00 & 1.00 \\
\hline HIV positive & $44(50.6)$ & $208(27.5)$ & $2.57(1.59-4.14)$ & $2.59(1.56-4.25)$ \\
\hline Unknown & $9(10.3)$ & $136(17.9)$ & $0.80(0.38-1.72)$ & $0.88(0.41-1.93)$ \\
\hline \multicolumn{5}{|l|}{ STI history } \\
\hline No & $65(74.7)$ & $532(70.3)$ & 1.00 & 1.00 \\
\hline Yes & $22(25.3)$ & $225(29.7)$ & $0.8(0.48-1.33)$ & $1.46(0.84-2.53)$ \\
\hline Between group variance & \multicolumn{4}{|c|}{0.245 (95\%Cl: $0.0446-1.247, p<0.0001)$} \\
\hline ICC & \multicolumn{4}{|l|}{0.069} \\
\hline
\end{tabular}

ICC Intra-cluster correlation coefficient. The between group variance and ICC was computed to see VIA test positivity (dependent variable) variability among type of health center cluster $s$ (independent variable) as per multilevel mixed effects models for logistic regression. ICC $=0.245 /\left(0.245+\boldsymbol{\pi}^{2} / 3\right)=0.245 / 3.535=0.069$

are apparently healthy and had no symptom. We are more concerned if there are noticeable and/or visible signs and symptoms, which is not true for screening programs like this."
Most participants mentioned that there is lack of adequate information about the existence of cervical screening, eligibility for screening, screening sites and time schedule for screening. Most women heard of 
cervical cancer screening but they did not know where it is provided. A study participant who did not visit a health center for screening stated that:

"I think all women in my community don't have information about cervical cancer screening but had they known the detailed information about it, I am sure they would have been screened. Sometimes I heard radio/TV advertainments but they don't convey detailed information about the disease, benefits and risks of screening, where and when to screen, etc."

Another in-depth participant added:

"Ethiopia has a good record of community health workers but their role in cervical cancer screening is very limited. They are teaching us about hygiene, diabetes mellitus, family planning and hypertension. It would be more cost-effective if cervical cancer screening is considered as one of the packages in community training or teaching."

A prevailing notion among the participant of the study was cervical cancer screening is only used for the detection of cancer that is already present. Some women refused to be screened as they thought that having cervical cancer screening is not beneficial while others believed that it is a service to be given for sick women only. A study participant who refused for screening stressed that:

"I don't think the screening for cervical cancer is important for healthy women of my age. I think it is better to screen those women who are sick or in menopausal age [...] because in most cases cervical cancer is very common in those women in my community."

\section{Cultural and religious beliefs}

Some of the participants mentioned that the health professionals' approach during the screening procedure was a barrier for screening. Participants mentioned that their culture is very sensitive towards examining female genital organ by male health professionals. This was strengthened by a screened in-depth interview participant:

"Before one year, I was examined for cervical cancer by a male health care provider and I was so ashamed when he asked me to undress. It was very difficult to accept and I think this might be because of our culture which is so sensitive to such things."

Bad perception about cancer as a whole also prevented them to be screened. They tried to associate it with religious beliefs and believed that it is their GOD's seek to prevent such types of bad things. Accordingly, some of them preferred to pray for God instead of screened and treated. They also heard and believed that the cancer treatment outcome is poor even if treated; so, it's better not to be screen rather than screened and told having cancer. One participant said:

"I preferred to die immediately rather than do the screening and being told having cervical cancer".

\section{Inaccessibility of screening services}

Some of the participants mentioned that cervical cancer screening service was not available in their vicinity and this might be contributed to the lower screening uptake. Furthermore, quite a large number of women had no information that the service is given free of charge. One of the interviewee stated that:

"I am not aware that the service is given freely. Most of us think that we have to pay for screening but we can't afford it. We heard that the screening is dump expensive in private hospitals in Addis Ababa."

\section{Discussion}

With the overall burden of cervical cancer projected to continue rising over the next decades, Ethiopia has introduced several initiatives to reduce its impact. Among others, cervical cancer screening program using VIA test has been implemented recently. To this effect, we assessed the VIA positivity rate among screened women and reasons for the low screening uptake. The VIA positivity rate was $10.3 \%$ which is slightly lower than the previous study done in South West Ethiopia (12.3\%) [23] and Sudan (12.7\%) [24], though the sample size in these studies was almost half and 1/7th of the present study, respectively. Although different study populations (HIV positive patients only), studies in Southern Ethiopia reported highest proportions of VIA positivity (22.1\%) [25], which is almost similar to Tanzania (17\%) [26]. The findings in the present study reveals that cervical cancer is still a significant public health problem for both HIV positive and negative women. This warns screening service provision should get special attention, knowing that early detection and treatment is more cost-effective than treating advanced disease [7].

Similar to previous studies [1, 27-29]; advanced age, having multiple sexual partners, being single or widowed, initiating first sexual intercourse at an early age and being HIV positive were found to be predictors of VIA positivity. Women aged $\geq 45$ years had higher odds of having VIA positive test result compared to those aged $\leq 24$ years. This is similar to studies conducted in Addis Ababa [28, 29] and Jimma [16]. All these associations have been already observed and that 
they are consistent with what we know of the etiology and natural history of the disease $[8,30]$.

Having multiple sexual partners and early age at first sexual intercourse were significantly associated with having positive VIA test results compared to their counterparts, and both factors are known to increase the chance of acquiring HPV infection [29]. Especially starting sexual intercourse at early age may increase the risk, because at young age, the cervix has an immature membrane thus making it more susceptible to ontological agents particularly high-risk type of HPV [31] and this has been substantiated by studies done elsewhere [23, 32-34]. The present study also found that being single or widowed were significantly associated with positive VIA test result compared to married women. This might be because those women may not be abstained or had a greater chance of having multiple sexual partners resulting in an increased risk of acquiring HPV infection. This calls for policymakers to devise mechanisms to improve their awareness about cervical cancer and available screening services.

Screening and early treatment of cervical cancer if detected remains the most effective way to reduce the mortality associated with the disease. But different studies including in Ethiopia showed cervical cancer screening uptake is still low, ranged from 7.3 to $23.5 \%$ [9-14, 35-37]. Concurrent to previous studies [12, 20, 35-38], our qualitative study revealed that lack of awareness or knowledge about cervical cancer and its causes, symptoms, fear of diagnosis and treatment among women decreased their participation rates in screening. On another note, women's unwillingness for screening was attributed to cultural and religious norms. This was expressed in several forms such as better to go to holy water and pray, the lack of desire to disrobe for the pelvic examination and concerns at being examined by male healthcare providers. Some participants in this study also did not know the presence of screening services and who will be screened. Hence, as part of the primary prevention strategies for cervical cancer, screening related educational programs need to emphasize on the value of the methods, when, how and for whom.

\section{Conclusions}

The VIA positivity among screened women was found to be 10.3\%. Having multiple sexual partners, being HIV positive, marital status and early age at initiation of sexual intercourse were identified as predictors of precancerous lesions of the cervix. Women perceived that the lack of awareness regarding cervical cancer and cervical cancer screening, inaccessibility of the screening service, cultural and religious beliefs including fear of the screening procedure; were the major barriers to cervical cancer screening uptake. This calls the need to improve the knowledge and awareness of the community about the disease and screening services through the existing health extension program.

\section{Supplementary information}

Supplementary information accompanies this paper at https://doi.org/10. 1186/s12905-020-01008-3.

Additional file 1. English version of survey form and in-depth interview guide

\section{Abbreviations}

HIV: Human immunodeficiency virus; HPV: Human papillomavirus; IUCD: Intrauterine contraceptive device; OCP: Oral contraceptives; STI: Sexually transmitted infection; VIA: Visual inspection with acetic acid

\section{Acknowledgments}

The authors would like to thank the Regional Health Bureau of Addis Ababa, administrative staff of each health center selected for the study and data collectors for their support throughout the study period. Finally, we would like to thank all those who participated in the qualitative interview and Professor Alemayehu Worku (Statistician and Epidemiologist) for his valuable guidance to compute intra cluster correlation and other statistical tests.

\section{Authors' contributions}

AMF and GBG carried out conceptualization of the research, visualize and validate the study design, performed the statistical analysis; write, review and edit both the original draft and final manuscript. TBT participated in the conceptualization and visualization of the study design and statistical analysis; collect the data and write the original draft manuscript. The authors read and approved the final manuscript.

\section{Funding}

Not applicable.

\section{Availability of data and materials}

All the data and materials used in this paper are available from the corresponding author upon reasonable request.

\section{Ethics approval and consent to participate}

The study protocol was approved by the Institutional Ethics Review Board of Addis Ababa Regional Health Bureau. Written permission was taken from all study health facilities (from the five health centers) to access and use data from cervical cancer screening registration log-book. Written informed consent which was approved by the ethics committee was also obtained from all in-depth interview participants after explaining the purpose and importance of the study. No emancipated minors were included for the in-depth interview and all were in the age range of 23 to 55 years. Individuals were informed that it is fully voluntary and they can withdraw from the study at any time or not to answer those they didn't want and this would not affect the service they get from the healthcare facilities. They were also informed that they would not receive any monetary incentive for participating in the study. The collected data were secured in a lockable cabinet, no identifiers were used and data were analyzed in aggregate to maintain confidentiality and anonymity of information.

\section{Consent for publication}

Not applicable.

\section{Competing interests}

The authors have stated that they have no conflicts of interest.

\section{Author details}

${ }^{1}$ Social and Administrative Pharmacy Unit, School of Pharmacy, College of Health Sciences, Addis Ababa University, P.O.Box: 1176, Addis Ababa, Ethiopia. ${ }^{2}$ Addis Ababa Health Bureau, Addis Ababa, Ethiopia.

Received: 5 June 2019 Accepted: 1 July 2020

Published online: 16 July 2020

\section{References}

1. Torre LA, Islami F, Siegel RL, Ward EM, Jemal A. Global cancer in women: burden and trends. Cancer Epidemiol Biomarkers Prev. 2017;26(4):444-57. 
2. Bray F, Ferlay J, Soerjomataram I, Siegel R, Torre L, Jemal A. Global cancer statistics 2018: GLOBOCAN estimates of incidence and mortality worldwide for 36 cancers in 185 countries. CA Cancer J Clin. 2018;68(6):394-424.

3. Ferlay J, Soerjomataram I, Dikshit R, Eser S, Mathers C, Rebelo M, et al. Cancer incidence and mortality worldwide: sources, methods and major patterns in GLOBOCAN 2012. Int J Cancer. 2015;136(5):E359-86.

4. Bruni L, Albero G, Serrano B, Mena M, Gómez D, Muñoz J, et al. ICO/IARC information Centre on HPV and cancer (HPV information Centre). Human papillomavirus and related diseases in EthiopiaSummary Report 17 June; 2019.

5. World Health Organization. International Agency for Research on Cancer and World Health Organization: GLOBOCAN 2018: estimated cervical cancer incidence and mortality; 2018. Available from: http://gco.iarc.fr.

6. EFMoH. National Cancer Control Plan 2016-2020. Dis Prev Control Dir. 2015: 1-83 Available from: http://bmg.bund.de/en.html.

7. WHO. Guidelines for screening and treatment of precancerous lesions for cervical cancer prevention. WHO Libr Cat Data. 2013;22-7. Available at: https://www.who.int/reproductivehealth/publications/cancers/screening_ and_treatment_of_precancerous_lesions/en/. Accessed 14 July 2020.

8. Shiferaw N, Salvador-Davila G, Kassahun K, Brooks MI, Weldegebreal T, Tilahun $Y$, et al. The single-visit approach as a cervical cancer prevention strategy among women with HIV in Ethiopia: successes and lessons learned. Glob Heal Sci Pract. 2016:4(1):87-98.

9. Kasa AS, Tesfaye TD, Temesgen WA. Knowledge, attitude and practice towards cervical cancer among women in Finote Selam city administration, west Gojjam zone, Amhara region, north West Ethiopia, 2017. Afr Health Sci. 2018;18(3):623-36. https://doi.org/10.4314/ahs.v18i3.20.

10. Aweke YH, Ayanto SY, Ersado TL. Knowledge, attitude and practice for cervical cancer prevention and control among women of childbearing age in Hossana town, Hadiya zone, southern Ethiopia: community-based crosssectional study. PLoS One. 2017;12(7):e0181415. https://doi.org/10.1371/ journal.pone.0181415.

11. Nega AD, Woldetsadik MA, Gelagay AA. Low uptake of cervical cancer screening among HIV positive women in Gondar University referral hospital, Northwest Ethiopia: cross-sectional study design. BMC Womens Health. 2018; 18(1):87Published 2018 Jun 7. https:/doi.org/10.1186/s12905-018-0579-z.

12. Tefera F, Mitiku I. Uptake of cervical cancer screening and associated factors among 15-49-year-old women in Dessie town, Northeast Ethiopia. J Cancer Educ. 2017;32(4):901-7.

13. Bayu H, Berhe Y, Mulat A, Alemu A. Cervical cancer screening service uptake and associated factors among age eligible women in Mekelle zone, northern Ethiopia, 2015: a community based study using health belief model. PLoS One. 2016;11(3):1-13.

14. Erku DA, Netere AK, Mersha AG, Abebe SA, Mekuria AB, Belachew SA. Comprehensive knowledge and uptake of cervical cancer screening is low among women living with HIV/AIDS in Northwest Ethiopia. Gynecol Oncol Res Pract. 2017;4:20. https://doi.org/10.1186/s40661-017-0057-6 eCollection 2017.

15. Nigussie T, Admassu B, Nigussie A. Cervical cancer screening service utilization and associated factors among age-eligible women in Jimma town using health belief model, south West Ethiopia. BMC Womens Health. 2019;19(1):127. https://doi.org/10.1186/s12905-019-0826-y.

16. Belete $N$, Tsige $Y$, Mellie $H$. Willingness and acceptability of cervical cancer screening among women living with HIV/AIDS in Addis Ababa, Ethiopia: a cross sectional study. Gynecol Oncol Res Pract. 2015;2(1):6.

17. Bezabih M, Tessema F, Sengi H, Deribew A. Risk factors associated with invasive cervical carcinoma among women attending Jimma University specialized hospital, Southwest Ethiopia: a case control study. Ethiop J Health Sci. 2015;25(4):345-52.

18. Getahun F, Mazengia F, Mulunesh Abuhay Zelalem B. Comprehensive knowledge about cervical cancer is low among women in northwest comprehensive knowledge about cervical cancer is low among women in Northwest Ethiopia. BMC Cancer. 2013;13(2):1-7.

19. Mitiku I, Tefera F. Knowledge about cervical cancer and associated factors among 15-49 year old women in Dessie town, Northeast Ethiopia. PLoS One. 2016;11(9):1-10.

20. Dulla D, Daka D, Wakgari N. Knowledge about cervical cancer screening and its practice among female health care workers in southern Ethiopia: a crosssectional study. Int J Womens Health. 2017;9:365-72.

21. Pourhoseingholi MA, Vahedi M, Rahimzadeh M. Sample size calculation in medical studies. Gastroenterol Hepatol Bed Bench. 2013;6(1):14.
22. Raykov T, Marcoulides GA. Intra-class correlation coefficients in hierarchical design studies with discrete response variables: a note on a direct interval estimation procedure. Educ Psychol Meas. 2015;75(6):1063-70. https://doi. org/10.1177/0013164414564052 Epub 2015 Jan 7.

23. Deksissa ZM, Tesfamichael FA, Ferede HA. Prevalence and factors associated with VIA positive result among clients screened at Family Guidance Association of Ethiopia, south west area office, Jimma model clinic, Jimma, Ethiopia 2013: a cross-sectional study. BMC Res Notes 2015;8:618. https:// doi.org/10.1186/s13104-015-1594-X.

24. Ibrahim A, Aro AR, Rask, Pukkala E. Cervical cancer screening in primary health care setting in Sudan: a comparative study of visual inspection with acetic acid and Pap smear. Int J Womens Health. 2012;4:67-73.

25. Gedefaw A, Astatkie A, Tessema GA. The prevalence of precancerous cervical cancer lesion among HIV-infected women in southern Ethiopia: a cross-sectional study. PLoS One. 2013;8(12):e84519.

26. Obure J, Olola O, Swai B, Mlay P, Masenga G, Walmer D. Prevalence and severity of cervical squamous intraepithelial lesion in a tertiary hospital in northern Tanzania. Tanzan J Health Res. 2009;11(4):163-9.

27. Kassa RT. Risk factors associated with precancerous cervical lesion among women screened at Marie stops Ethiopia, Adama town, Ethiopia 2017: a case control study. BMC Res Notes. 2018;11:1-5.

28. Teame H, Addissie A, Ayele W, Hirpa S, Gebremariam A, Gebreheat G, et al. Factors associated with cervical precancerous lesions among women screened for cervical cancer in Addis Ababa, Ethiopia: a case control study. PLoS One. 2018;13(1):e0191506.

29. Abate SM. Cervical cancer : open access trends of cervical cancer in Ethiopia. Cerv Cancer. 2015;1(1):1-4.

30. Ghim S, Basu PS, Jenson AB. Cervical cancer : etiology, pathogenesis, treatment, and future vaccines. Asian Pac J Cancer Prev. 2002;3(July 2017): 207-14.

31. Plummer $\mathrm{M}$, Peto J, S F. Time since first sexual intercourse and the risk of cervical cancer. Int J Cancer. 2014;130(11):2638-44.

32. Schiffman M, Wentzensen N, Wacholder S, Kinney W, Gage JC, Castle PE. Human papillomavirus testing in the prevention of cervical cancer. J Natl Cancer Inst. 2011:103(5):368-83.

33. Biswas LN, Manna B, Maiti PK, Sengupta S. Sexual risk factors for cervical cancer among rural Indian women: a case-control study. Int J Epidemiol. 1997;26(3):491-5.

34. Ncube B, Bey A, Knight J, Bessler P, Jolly PE. Factors associated with the uptake of cervical cancer screening among women in Portland, Jamaica. N Am J Med Sci. 2015;7(3):104-13.

35. Morema EN, Atieli HE, Onyango RO, Omondi JHOC. Determinats of cervical cancer screening services uptake among 18-49 years old women seeking services at Jaramogi Oginga Odinga teaching and referral hospital. BMC Health Serv Res. 2014;6(14):1-5.

36. Gakidou E, Nordhagen S, Obermeyer Z. Coverage of cervical cancer screening in 57 countries: low average levels and large inequalities. PLoS Med. 2008;5(6):0863-8.

37. Lyimo FS, Beran TN. Demographic, knowledge, attitudinal, and accessibility factors associated with uptake of cervical cancer screening among women in a rural district of Tanzania: three public policy implications. BMC Public Health. 2012;12(1):22.

38. Teame H, Gebremariam L, Kahsay T, Berhe K, Gebreheat G, Gebremariam G. Factors affecting utilization of cervical cancer screening services among women attending public hospitals in Tigray region, Ethiopia, 2018; case control study. PLoS One. 2019;14(3):e0213546Published 2019 Mar 14. https://doi.org/10.1371/journal.pone.0213546.

\section{Publisher's Note}

Springer Nature remains neutral with regard to jurisdictional claims in published maps and institutional affiliations. 